\title{
INDISCIPLINA NA EDUCAÇÃO INFANTIL
}

\author{
Antônia Avanildes Cardozo ${ }^{1}$ \\ Elenice Aparecida Arruda da Costa Silva ${ }^{2}$ \\ Eliane Maria de Lima Paixão ${ }^{3}$ \\ Mara Jovino Nascimento Hofferer ${ }^{4}$ \\ Sara Lima Nascimento ${ }^{5}$
}

RESUMO: O presente trabalho tem como objetivo discutir acerca da indisciplina no espaço da Educação Infantil, mostrando que a indisciplina no contexto histórico vem sendo ligada a diversos aspectos sociais e educacionais e pensando no desenvolvimento da criança. A disciplina é um dos componentes fundamentais no aspecto educacional, assim como o envolvimento da família e da instituição de ensino através de um bom planejamento para conseguir bons resultados, e com o intuito de solucionar esses problemas que acabam prejudicando os alunos, professores e toda a comunidade escolar, pois não afeta somente as instituições mas, toda a comunidade local. A indisciplina está muito ligada ao meio que a criança vive por isso a importância do envolvimento de toda a sociedade.

Palavras-chave: Educação infantil. Indisciplina. Escola.

ABSTRACT: The present work aims to discuss about indiscipline in the space of Early Childhood Education, showing that indiscipline in the historical context has been linked to various social and educational aspects and thinking about the child's development. Discipline is one of the fundamental components in the educational aspect, as well as the involvement of the family and the educational institution through good planning to achieve good results, and in order to solve these problems that end up harming students, teachers and the whole school community, as it affects not only the institutions but the entire local community. The indiscipline is closely linked to the environment that the child lives, hence the importance of the involvement of the whole society.

Keywords: Child education. Indiscipline. School.

\footnotetext{
${ }^{1}$ Graduada em Pedagogia pela Universidade Federal do Rio Grande do Sul - UFRG, Especialista em Educação Ambiental pelas Faculdades Integradas Mato-Grossenses de Ciências Sociais e Humanas - ICE.

2 Graduada em Pedagogia pela Universidade Anhanguera - UNIDERP, Especialista em Educação Infantil e Alfabetização pelas Faculdades Integradas de Várzea Grande - FIAVEC.

${ }^{3}$ Graduada em Pedagogia pelas Faculdades Integradas Mato-Grossenses de Ciências Sociais e Humanas - ICE, Especialista em Educação Infantil e Alfabetização pelas Faculdades Integradas Mato-Grossenses de Ciências Sociais e Humanas - ICE.

${ }^{4}$ Graduada em Pedaogia pela Universidade de Cuiabá - UNIC, Especialista em Educação Infantil e Alfabetização pelas Faculdades Integradas de Várzea Grande - FIVE.

${ }^{5}$ Graduada em Pedagogia pela Faculdade INVEST de Ciências e Tecnologia, Graduada em Letras / Literatura pela Universidade Federal de Mato Grosso, Especialista em Educação de Jovens e Adultos - EJA pela Faculdade Integrada de Várzea Grande - FIAVEC, Especialista em Alfabetização e Letramento pela Faculdade Metropolitana.
} 


\section{INTRODUÇÃO}

A educação infantil é a fase que envolve crianças de o a 6 anos, considerada a primeira fase da educação básica. Podemos destacar que a infância é um período crucial na vida das crianças, pois é nesta fase que estas adquirem competências fundamentais para o desenvolvimento de competências que irão influenciar a sua vida adulta.

A educação infantil é a base da aprendizagem, preparando a criança para a aprendizagem. Socializar, desenvolver habilidades, melhorar o desempenho escolar futuro, proporcionando às crianças resultados superiores quando chegam no ensino fundamental.

A educação para a cidadania constitui o caráter socializante essencial na fase didática da educação infantil e é neste campo das relações e interações sociais entre crianças da mesma idade ou próximas e das interações entre elas e os professores que os conflitos podem surgir. . Ainda nesse contexto, pode-se apontar que na educação infantil meninos e meninas estão no início de seu desenvolvimento social, ampliando suas relações de convivência na comunidade e na vida escolar.

Portanto, este trabalho tem como objetivo apresentar uma discussão teórica sobre a indisciplina na educação infantil, a fim de abordar seus conceitos, causas e consequências dessa problemática que atinge todos os envolvidos no contexto escolar. Este estudo abordará também pesquisas recentes na área da educação infantil que discutem a existência desse dilema educacional nesta fase inicial da educação básica, a fim de apresentar pesquisas que apresentem soluções para minimizar o impacto desse problema. sobre o processo de educação infantil.

\section{DESENVOLVIMENTO}

\section{I Educação Infantil}

A história da educação infantil no Brasil é recente. A constituição de 1988 reconhece às crianças pequenas o direito à educação materna e pré-escolar, portanto a educação materna e pré-escolar está inserida na política educacional, seguindo uma concepção pedagógica e não mais assistencialista.

Essa perspectiva pedagógica vê a criança como um ser social e histórico pertencente a uma determinada classe social e cultural. Nesse sentido, também, o Referencial Estrutura 
Curricular Nacional para a Educação Infantil (1998, p. 23) relata que a instituição de educação infantil deve tornar os elementos culturais acessíveis a todas as crianças que frequentam indiscriminadamente, enriquecendo seu desenvolvimento e inclusão.

De acordo com Paschoal e Machado (2009) as primeiras tentativas de apoio as crianças aconteceram por meio de creches de caráter caritativo, com o objetivo de ajudar mulheres que trabalhavam fora de casa e viúvas indefesas. Então, os primeiros jardins de infância eram apenas um lugar para as crianças ficarem, não tinha um caráter pedagógico.

Andrade (2010) relata que as creches no Brasil surgiram para minimizar os problemas sociais decorrentes da miséria de mulheres e crianças, revelando sua natureza de cuidado e tutela voltada para o cuidado de crianças e famílias empobrecidas. Isso deu às mães a oportunidade de trabalhar fora de casa para sustentar a família, pois poderiam deixar os filhos na creche. $\mathrm{O}$ advento da creche permitiu que as mães trabalhassem sem se preocupar com os filhos.

Paschoal e Machado (2009) lembram que a partir dessa lei as creches, antes vinculadas ao setor de assistência social, passaram a ser responsabilidade da educação. O princípio foi tomado como diretriz de que essas instituições não só atendem às crianças, mas devem, prioritariamente, desenvolver um trabalho educativo. Nesse sentido, a creche deixa de ter apenas esse sentido de cuidado e passa a ter uma responsabilidade educacional e social, contribuindo para o desenvolvimento das crianças.

$\mathrm{Na}$ visão de Andrade (2010) a temática da creche se legitima como extensão do direito universal à educação para crianças de o a 6 anos, como espaço de educação infantil, além da educação familiar.

A Constituição Federal de 1988, do Estatuto da Criança e do Adolescente der199o, a Lei de Diretrizes e Bases da Educação Nacional de 1996, destacam a instituição da Educação Infantil na composição dos níveis escolares, como primeira etapa da Educação Básica. Segundo LDB, a finalidade da educação infantil é promover o desenvolvimento integral da criança até seis anos de idade, complementando a ação da família e da comunidade (BRASIL, 1996).

A educação infantil ganhou forças por meio da Lei das Diretrizes e Bases da Educação nacional, LDB № 9394/1996, declara que a Educação Infantil inicia dos o aos 3 anos de idade para estar numa creche, prosseguindo de 4 a 5 anos de idade como pré-escola, 
tornando-se Educação Infantil, também um ciclo de 5 anos de formação contínua e parte integrante, constituidora, da Educação Básica brasileira.

A LDB em seu art. 29, destaca que a Educação Infantil como a primeira etapa da Educação Básica e tem como finalidade o desenvolvimento integral da criança até cinco anos de idade, em seus aspectos físicos, psicológico e social, complementando a ação da família e da comunidade.

No seu art. 30, a LDB relata que a Educação Infantil será ofertadas em creches para crianças de até três anos de idade e em pré-escolas para crianças de quatro a cinco anos de idade.

Paschoal e Machado (2009) ressaltam que por meio de leis institucionalizadas, pôde-se reconhecer o grande avanço nos direitos da criança pequena, visto que a educação infantil está próxima ao primeiro nível da educação básica, embora não seja obrigatória, é um direito da criança e visa criar o direito condições para o desenvolvimento da educação. o bem-estar da criança quanto ao desenvolvimento físico, motor, emocional, social, intelectual e a expansão de suas vivências. A educação infantil ganhou importância no ambiente escolar, tornando-se a base para o desenvolvimento intelectual e social das crianças.

Para Barreto, (2010) a educação infantil tem uma função educativa. Como ponto de partida, utiliza-se a realidade e o conhecimento infantil, que é ampliado por meio de atividades que tenham significados concretos para a vida das crianças e garantam novos conhecimentos. A autora também enfatiza que os educadores infantis devem se preocupar mais com a organização e execução de atividades que contribuam para o desenvolvimento das crianças de o a 5 anos

Cabe ao professor individualizar as situações de aprendizagem oferecidas às
crianças, considerando suas capacidades afetivas, emocionais, sociais, cognitivas
assim como os conhecimentos que possuem dos mais diferentes assuntos e suas
origens socioculturais diversas. Isso significa que o professor deve planejar e
oferecer uma gama variada de experiências que responda, simultaneamente, às
demandas do grupo e as individualidades de cada criança (REFERENCIAL
CURRICULAR NACIONAL PARA A EDUCAÇÃO INFANTIL, I998, p.32).

Segundo Barreto et al (2010) na educação infantil, o professor deve estar preparado para lidar com crianças de diferentes personalidades e dificuldades de aprendizagem, por isso o professor deve levar em consideração que cada criança tem um ritmo de aprendizagem 
diferente e proporcionar às crianças uma educação baseada nas condições de aprendizagem. de cada um que consideram único e com características próprias. A autora destaca ainda que o grande desafio da educação infantil e de seus profissionais é compreender, conhecer e reconhecer o modo especial como as crianças estão e estão no mundo.

Barretos et al (2010) destaca que crianças de o a 5 anos têm direito à educação por meio da LDB e devem ser aceitas por instituições da rede de ensino e do estado. A educação infantil é, portanto, um direito da criança, um dever do Estado e uma opção da família.

Conforme Oliveira (2005, p.49) para que as propostas pedagógicas de creches e préescolas atendam aos dispositivos legais, elas deverão criar condições para que as crianças interajam com adultos e outras crianças em situações variadas, construindo significações acerca do mundo e de si mesmas, enquanto desenvolvem formas mais complexas de sentir, pensar e solucionar problemas, em clima de autonomia e cooperação.

Para Andrade (2010) o reconhecimento da natureza educativa das creches implica o rompimento com o seu patrimônio assistencial, bem como a definição de propostas pedagógicas para a primeira infância que possam garantir a aprendizagem $e$ desenvolvimento das crianças, respeitando as particularidades desta faixa etária.

Barreto et al (2010) dizem que a educação infantil envovle todas as modalidades educativas vividas pelas crianças pequenas na família e na comunidade, antes mesmo de atingirem a idade da escolaridade obrigatória.

Melo (2017) destaca que a Educação Infantil é a principal base de aprendizagem, socializa, desenvolve competências, melhora o desempenho escolar no futuro, promove o lúdico, a ética, a cidadania e os laços afetivos, proporcionando às crianças resultados eficazes para a vida.

\subsection{Indisciplina}

A indisciplina escolar infantil é um dos maiores desafios no contexto escolar, tanto para os alunos como para os professores e familiares. Além de prejudicar o processo de aprendizagem, esse tipo de comportamento pode dificultar a construção de relacionamentos entre os envolvidos no ambiente escolar. 
De acordo com Silva (2014) a indisciplina tem se tornado um desafio extremamente crescente e com isso tem gerado no espaço escolar uma aprendizagem insatisfatória, pois o ambiente escolar está estressado e desmotivante.

Por isso, é importante que a ação do professor desperte o interesse dos alunos em sala de aula, fomentando suas habilidades, criando estímulos e tornando o aprendizado efetivo.

Para Durante (2015) a indisciplina é um dos fatores que mais preocupa a rede de ensino, sendo um dos vilões da não aprendizagem do aluno. Os professores, por sua vez, não sabem lidar com as questões relacionadas à indisciplina e os alunos que se destacam por esse tipo de comportamento são tratados de forma que gera ainda mais indisciplina.

Ferreira (2008) define a indisciplina como um procedimento, ato ou dito contrário à disciplina. O autor ainda explica a palavra disciplina como (a) regime de ordem imposta ou mesmo consentida; (b) ordem que convém ao bom funcionamento de uma organização; (c) relações de subordinação do aluno ao mestre; (d) submissão a um regulamento, etc. Para Vasconcelos, (2013) a indisciplina é a negação da disciplina. É a incapacidade de mediar os conflitos dialéticos entre adequação e transformação.

Para Antunes (2013) a disciplina no seu sentido etimológico, se associa a ideia de educar, instruir, aplicar e fundamentar princípios morais, por sua vez, a indisciplina expressa desobediência, confusão ou negação da ordem.

A indisciplina ao se torna excessiva pode ser considerada uma alteração patológica que impossibilita o comportamento adequado de uma pessoa na sociedade.

Nos dicionários de filosofia encontramos a seguinte definição: "função negativa ou coercitiva de uma regra ou de um conjunto de regras, que impede a transgressão à regra” e “coação graças à qual a tendência permanente que nos leva a desviar-nos de certas regras é limitada e finalmente extirpada" (ABBAGNANO, I999, p. 289; CAYGILL, 2000, p. 104).

Desse modo, podemos dizer que indisciplina é a atitude que se relaciona com os deveres pessoais e que refletem na falta da ordem, na determinação e na projeção de metas.

Segundo Durante (2015) a indisciplina é também conhecida por outros nomes, que podem soar menos agressivos, como "comportamento inadequado" e "falta de limites", ou chocar quem ouve, como "violência escolar". Independentemente de como seja identificada, a indisciplina constitui uma das queixas mais frequente entre pais e professores. 
A indisciplina escolar tem sido o alvo de inúmeras discussões entre os educadores brasileiros dos diferentes níveis de ensino, desde a Educação Básica até o Ensino Superior conforme podemos comprovar nos estudos realizados por Aquino (1996), Garcia (2008) e Torres (2008).

$\mathrm{Na}$ opinão de Barbosa (2009) a indisciplina apresenta-se como um importante obstáculo no processo ensino-aprendizagem, prejudicando o exercício da função docente e o aproveitamento dos conhecimentos ministrados por parte dos alunos envolvidos. $\mathrm{O}$ autor ainda destaca que esta tem sido uma preocupação constante entre os educadores e tem mobilizado a comunidade escolar em geral, tornando-se o principal foco das reuniões de pais e mestres, conselhos de classe, etc.

Segundo Aquino (1998) as crianças dos nossos dias atuais não têm limites, não reconhecem a autoridade, não respeitam as regras, a responsabilidade por isso é dos pais, que teriam se tornado muitos permissivos.

A indisciplina quando se apresenta desde a infância é um hábito difícil de superar, sendo assim os educadores devem ser extremamente paciente com seus alunos e trata-los com delicadeza.

Para Oliveira (2005) além da indisciplina causar danos ao professor e ao processo ensino-aprendizagem, o aluno também é prejudicado pelo seu próprio comportamento: ele não aproveitará que se nada dos conteúdos ministrados durante as aulas, pois o barulho e a movimentação impedem qualquer trabalho reprodutivo. Para uma educação idealmente construída, a disciplina deveria ser consequência voluntária da escolha livre e, como consequência da disciplina, a liberdade deveria enriquecer-se de possibilidade, não sendo antagônicos os dois princípios de liberdade e de disciplina.

Para Sá (2017) a escola deve ter um Projeto Político Pedagógico que aborde as questões da indisciplina. Segundo o autor, a escola deve convocar famílias, alunos, professores, ou toda a comunidade escolar, para elaborar o PPP envolvido, pois isso facilita o cumprimento.

Sá (2017) também ressalta a importância da promoção da formação continuada dos professores, assim eles poderão adquirir conhecimentos para liderarem os conflitos adequadamente e contribuírem para a elevação da pacificidade dentro e fora da sala de aula. 
O aluno está cada vez mais distante das boas questões educacionais, menos comprometido com a própria formação e muito mais agressivo.

\subsection{Causas e consequências da indisciplina infantil}

As causas da indisciplina ou do comportamento inadequado são inúmeras, portanto, uma avaliação das principais causas e consequências é necessária para criar mecanismos para enfrentar esse grande obstáculo na educação infantil.

$\mathrm{Na}$ visão de Garcia (1999) as várias causas da falta de disciplina escolar podem ser divididas em dois grupos: causas externas e causas internas. Para o autor, as causas externas estão ligadas às influências da mídia, da violência social e do ambiente familiar. As causas dentro da escola incluem, por sua vez, o ambiente escolar e as condições de ensino-aprendizagem, as formas de interação humana, o perfil dos alunos e sua capacidade de adaptação ao esquema escolar. Portanto, existem motivos para a indisciplina na relação entre professores e os próprios alunos, e as formas de intervenção disciplinar praticadas pelos professores podem reforçar ou mesmo criar formas de indisciplina.

Cury (2017) diz que as causas da indisciplina são: falta de interesse nas aulas; dificuldade de dosar as ações contra a indisciplina; violência gerada por violência sofrida. Segundo o autor a falta de interesse nas aulas é uma das principais dificuldades da educação escolar, pois muito alunos comparecem à aula apenas por obrigação, não se envolvem nas atividades propostas e tornam-se apáticos. Tal desinteresse pode ser porque eles não percebem a utilidade dos conteúdos apresentados ou devido a uma didática monótona do professor quando ele ensina tudo do mesmo jeito, as aulas são sempre iguais. Outra causa da indisciplina considerada por Cury (2017) é dificuldade de dosar as ações contra a indisciplina, isso ocorre quando os combinados da aula não são respeitados, desta forma, cabe ao professor balancear as medidas de conscientização conforme a gravidade das ações, os pontos mais graves são xingamentos e agressões entre colegas, estes precisam de maior intervenção.

A última causa da indisciplina considerada pelo autor é a violência gerada por violência sofrida, a falta de medidas preventivas ou de conscientização em casos de violência ou bullying pode nutrir um sentimento de injustiça e abandono por parte das crianças e jovens que são alvos dessas ações. Da mesma forma, aqueles que praticam esses atos podem mais 
facilmente naturalizá-los e repeti-los, gerando um gatilho para a violência generalizada e um círculo vicioso de indisciplina e hostilidade.

Segundo Vasconcelos (2004) a indisciplina pode ter suas causas encontradas em cinco grandes grupos: Sociedade, família, escola, professor e aluno.

Para Freitas (2016), a indisciplina é uma das questões mais discutidas no âmbito escolar, este assunto constantemente gera muita polêmica, as causas são inúmeras e dificilmente se chega a uma conclusão.

A indisciplina na educação infantil é manifestada de formas bem pecualirres e diferentes das que ocorrem em idades mais avançadas, porem vale ressaltar que algumas crianças desde que começam a frequentar a escola, já demonstram algum tipo de indisciplina.

Ainda segundo Freitas (2016) uma das causas da indisciplina infantil é a família, pois os alunos muitas vezes vêm de lares desestruturados onde os pais não se respeitam e assim reproduzem o que presencia em casa na escola. Desta forma a experiência do convívio familiar é a maior apontada como causadora dos problemas de indisciplina, uma vez que muitas crianças têm como base a falta de limites em casa.

Para Oliveira (2009) a indisciplina na sala de aula causa desperdício de tempo, desgaste dos professores por trabalharem em clima de desordem, pela perda do sentido e da eficácia e a diminuição da autoestima pessoal que leva sentimento de frustração, desanimo e ao desejo de abandono da profissão. Sendo assim atos indisciplinares compromete o estado emocional do professor, gerando sentimento de frustração e desanimo.

Banaletti e Dametto (2015) relatam que o problema da indisciplina, antes de ser algo pessoal relativo ao professor, é uma questão institucional, e assim precisa ser trabalhada.

De acordo com Pimenta (2012) outro fator que contribui para indisciplina infantil é o fato dos pais passarem pouco tempo com os filhos, por muitas razões, entre elas a questão financeira, que faz com que os pais se ausentem por causa do trabalho, não permitindo o acompanhamento mais de perto do desenvolvimento em relação a questões de valores para as crianças.

Em geral, a principal consequência da indisciplina é o ensino e a aprendizagem, o processo de desenvolvimento das crianças fica prejudicado, então a escola junto com a família deve trabalhar em conjunto para minimizar esse problema. 


\section{CONCLUSÃO}

A falta de disciplina foi intensamente vivenciada na escola é fonte de estresse nas relações interpessoais, principalmente em relação às situações de conflito em sala de aula. Mas a falta de disciplina na escola não é apenas um "problema” ela também tem algo a dizer sobre o ambiente escolar e a necessidade de desenvolvimento educacional e institucional.

A indisciplina é um grande problema nas instituições de ensino e medidas internas são necessárias para atuar preventivamente nessa questão, o que dificulta tanto o desenvolvimento do ensino e da aprendizagem quanto o desenvolvimento social das crianças.

A intensidade e o caráter da indisciplina hoje parecem menos à necessidade de transformação do que à necessidade de inovação da escola, que deve buscar novos métodos para trabalhar um assunto tão complexo que não tem um processo de causa única e no qual a família também está envolvida.

As instituições devem buscar o apoio da família e da sociedade para trabalhar de perto todos esses aspectos da indisciplina. Não só a escola deve estar em primeiro plano com esse problema, pois a indisciplina tem seus problemas internos que surgem dentro da escola e também aspectos externos onde a escola não tem tanta abrangência e é preciso unir todos para poder desenvolver a criança não é afetada.

$\mathrm{O}$ artigo em questão foi relevante porque abordou um assunto tão delicado que precisa ser tratado dentro de instituições que os pais muitas vezes não aceitam bem quando se diz que seu filho tem problema de disciplina, e esse trabalho mostrou que através da participação de todos, é possível construir uma educação de qualidade.

\section{REFERÊNCIAS}

ABBAGNANO, N. Dicionário de Filosofia. 3. ed. São Paulo: Martins Fontes, I999.

ANDRADE, LBP. Educação infantil: discurso, legislação e práticas institucionais. São Paulo: Editora UNESP; São Paulo: Cultura Acadêmica, 20 ı. 
AQUINO, Júlio Croppa. A Indisciplina e a Escola Atual. Rev. Fac. Educ. vol.24 n. 2 São Paulo July/Dec. 1998.

AQUINO, J. (org.). Indisciplina na escola: alternativas teóricas e práticas. 2. ed. São Paulo: Indisciplina na escola Summus, 1996a.

CAVAlCANTE, Ana Caroline Oliveira. A importância da educação infantil para o desenvolvimento global da criança. Disponível em:https://www.portaleducacao.com.br. Acesso em 08/1I/202I.

CAYGILL, H. Dicionário Kant. Rio de Janeiro: Jorge Zahar, 2000.

BARRETO, L. G. M.; SILVA, N. ; MELO, S. S. A história da educação infantil. Centro de Educação Infantil Eusébio Justino de Camargo Nova Olímpia - MT, 2010.

CURY, Augusto. Indisciplina escolar infantil: causas, consequências e como combatê-la, 2017. Disponível em: https://escoladainteligencia.com.br. Acesso em 08/II/202I.

FERREIRA, A. M. A. Gênese da indisciplina na relação professor aluno. IX Congresso Nacional de Educação- EDUCERE. III Encontro Sul Brasileiro de Psicopedagogia 26 a 29 de outubro de 2009- PUCPR. Disponível em: http://www.pucpr.br. Acesso em o8/II/202I.

GARCIA. J. Indisciplina na escola: Uma Reflexão Sobre: a Dimensão Preventiva. R. paran. Desenv., Curitiba, n.95, jan./abr. 1999, p. IoI-108. Disponível em: http://www.ipardes.gov.br. Acesso em 08/II/202I.

GIL, Antonio Carlos. Como elaborar projetos de pesquisa. 4. ed. São Paulo: Atlas, 2008.

GONÇALVES, Josiane Peres. A falta de limites em crianças na educação infantil segundo a perspectivas das professoras. Disponível em: http://www.pucpr.br. Acesso em 08/II/202I. 
LEITE, Gisele. A importância da Educação Infantil. Disponível em: http://www.administradores.com.br. Acesso em II/o8/202I

MAlHOTRA, N. K. Pesquisa de marketing: uma orientação aplicada. Porto Alegre: Bookman, 2004.

MARCONI, M. A.; LAKATOS, E. M. Técnicas de pesquisa. 4. ed. São Paulo: Atlas, I999.

MEDEIROS, J. B. Redação científica. II. ed. São Paulo: Atlas, 2oı. MELLO, Vera Regina Correa. A importância da Educação Infantil. Disponível em: http://educacao.estadao.com.br. Acesso em 08/II/2021.

MOURA, Aline Alencar S.; GONÇALVES, Roziane dos Santos; LIMA, Valéria Assunção. A Importância da Educação Infantil para o Amplo Desenvolvimento da Criança. Disponível em http://www.pedagogia.com.br. Acesso em 08/II/202I.

OLIVEIRA, Rosimary L.G. Reflexões sobre a indisciplina escolar a partir de sua diversidade conceitual. IX Congresso Nacional de Educação - Educere. PUCPR, 26 a 29 out. 2009. P.4503-4514. Disponível em: http://www.pucpr.br. Acesso em 08/II/202I.

PASCHOAL, J. D.; MACHADO, M. C. G. A história da educação infantil no Brasil: Avanções, retrocessos e desafios dessa modalidade Educacional. Revista HISTEDBR Online, Campinas, n.33, p.78-95, mar. 2009.

PIMENTA, Kedna Gomes, LOUZADA, Shênia Soraya Soares. A indisciplina na percepção de educadores e algumas possibilidades. Disponível em: http://facos.edu.br. Acesso em 08/II/202I. 
ROSSINI, Maria Augusta Sanches. Pedagogia Afetiva. 4. ed. Rio de Janeiro: Vozes, 2001. SÁ, Robison. A indisciplina na escola, 2015. Disponível em: https://www.infoescola.com. Acesso em 08/II/2021.

SILVA, Margarete Virgínia Gonçalves; FERREIRA, Jacques de Lima; GALERA, Joscely Maria Bassetto. A indisciplina Escolar enquanto desafio na formação do professor: uma realidade posta na sociedade contemporânea. Disponível em: http://www.pucpr.br. Acesso em 08/II/202I.

TORRES, R. Indisciplina na Educação Superior. In: SEMINÁRIO INDISCIPLINA NA EDUCAÇÃO CONTEMPORÂNEA, 4. Curitiba, 2006, Anais... Curitiba: UTP, 2008, p. 156- 167. CD.

VASCONCELLOS, Celso. Disciplina e Indisciplina na Escola. Revista Presença Pedagógica, Belo horizonte, MG. v. 19, n. 112. p. 5-13, set/2013. 